\title{
Omurga metastazları
}

\author{
Spinal metastases
}

\author{
Mert Çiftdemir, Murat Erem
}

Trakya Üniversitesi Tıp Fakültesi, Ortopedi ve Travmatoloji Anabilim Dalı, Edirne

\begin{abstract}
Omurgada en sık görülen tümörler, karsinom metastazları ve hematolojik malignitelerdir. Onkolojik tanı ve tedavideki teknolojik ilerlemeler kanser hastalarının ömrünün uzamasına imkân sağlamıştır. Bu nedenle, omurga metastazlı olguların sayısı her geçen gün artmaktadır. Ancak, buna paralel olarak, günümüzde omurga metastazlı olguların tanı ve tedavisi alanında da ilerlemeler kaydedilmiştir. Omurga metastazını destrüksiyon ve nörolojik defisit oluşmadan tanımak tedaviyi de kolaylaştıracaktır. Omurga metastazlı olguların tedavisinde hedef, ağrı kontrolünün yanı sıra omurga stabilitesinin ve nörolojik durumun desteklenmesi, korunması ve restorasyonu olmalıdır. Omurga metastazının uygun şekilde tedavisi, olguların yaşam kalitesinde ve onkolojik tedaviye uyumlarında artış sağlar.
\end{abstract}

Anahtar sözcükler: karsinom metastazı; omurga metastazı; metastatik spinal kord basısı; Batson venöz pleksusu
The most common tumors of the spine are metastases and haematologic malignancies. Technologic improvement regarding oncological diagnosis and treatment leads to longer survival of cancer patients. Therefore, cases with spinal metastases are increasing consistently. However, parallel to this issue, there is also improvement upon diagnosis and treatment of spinal metastases. Diagnosis of spine metastasis before any major destruction or neurological compromise will facilitate its treatment. Pain control alongside maintaining and restoring the spinal stability, and neurological functions should be aimed in the treatment of spinal metastases. Appropriate treatment of spinal metastasis increases the patient's quality of life and compatibility to oncological treatment.

Key words: carcinoma metastasis; spine metastasis; metastatic spinal cord compromise; Batson's venous plexus skelet sistemi, akciğer ve karaciğerden sonra iç organ kanserlerinin en sık metastaz yaptığı üçüncü organdır. Kanserlerin kemiğe yaptığı metastazların çoğu da omurga metastazıdır. ${ }^{[1]}$ Günümüzde kanser tedavisi ve hasta bakımı alanındaki teknolojik ilerlemeler, onkoloji hastalarının daha uzun yaşamasına imkân sağlamaktadır. Bu durum, omurga metastazı olgusu sayısının da her geçen gün artmasına neden olur. Ancak, buna paralel olarak, günümüzde omurga metastazlı olguların tanı ve tedavisi alanında da ilerlemeler kaydedilmiştir. Omurga metastazını destrüksiyon ve nörolojik defisit oluşmadan tanımak tedaviyi de kolaylaştıracaktır. Bu derlemede, omurga metastazlarına genel yaklaşım ve omurga metastazIı bir olguda tanı ve tedavi için izlenecek yöntem ele alınmaktadır.

\section{EPIDEMIYOLOJi ve PATOGENEZ}

Kanserden ölen hastaların otopsilerinde \%70'e varan oranda omurga metastazına rastlanırken, bu hastaların ancak yaklaşık \%10'unun semptomatik olduğu da bir gerçektir. ${ }^{[2]}$ Yurdumuz için sağlıklı bir veri bulunmamakla birlikte, Amerika Birleşik Devletleri'nin verilerine göre yıllık kansere bağlı ölüm sayısı 550.000 iken, metastatik spinal kord kompresyonu olgusu sayısının yıllık 20.000 civarı olduğu bildirilmektedir. ${ }^{[3]}$

Omurgaya en sık metastaz yapan kanserler meme, prostat, akciğer, böbrek kanserleri ve retiküloendoteliyal sistem maligniteleridir. Kemikte lenfatik sistem olmadığından kemik metastazları hematojen yolla olur. Akciğer kanserleri aorta ve arteriyel dolaşım yoluyla kemiğe doğrudan metastaz yapma yeteneğine sahipken,

- İletişim adresi: Doç. Dr. Mert Çiftdemir, Trakya Üniversitesi Tıp Fakültesi Ortopedi ve Travmatoloji Anabilim Dalı, Balkan Yerleşkesi, 22030 Edirne Tel: 0284 - 2357641 / 4704 e-posta: mertc@trakya.edu.tr

- Geliş tarihi: 19 Ağustos 2019 Kabul tarihi: 22 Ekim 2019 
diğer kanserler vena cava sistemi (akciğerler tarafindan filtre edilir) ve vena porta sistemi (karaciğer tarafından filtre edilir) yolu ile kemiğe ulaşır. ${ }^{[4]}$ Batın içi organ kanserleri lenfatik sistem ve ductus thoracicus yolu ile vena cava superior'a ulaşarak karaciğerin filtrelemesinden kaçarken, özellikle küçük hücreli akciğer kanserlerinin de akciğerin filtrelemesini geçerek venöz dolaşıma ulaşabildiği gösterilmiştir. ${ }^{[4]}$ Elbette, bir kanserin omurgaya metastaz yapabilmesi için venöz dolaşıma giriyor olması yetmez; tümör hücrelerinin dokulara yerleşebilmek için uygun koşulları ve ortamı da elde etmeleri gerekir. Omurgayı çepeçevre saran, lomber bölgede pelvis, proksimal femur venleri ve vena cava inferior ile, servikal bölgede ise baş, boyun ve yüzün venleri ve vena cava superior ile ilişki içinde, kapaksız bir venöz ağ olan Batson venöz pleksusunda kan çok düşük bir basınçla yavaşça akar. Karın içi basıncı artıran her durum, vena cava sistemindeki venöz kanın Batson pleksusuna karışmasına neden olur. Bu durum, metastatik embolilerin yine akciğer ve karaciğerin filtrelemesinden kaçışının bir diğer yoludur. Omurga metastazının patogenezinde rol oynayan diğer bir husus da; özellikle torakal omurga korpuslarında en bol miktarda bulunan hematopoetik kemik iliğinin zengin sinüsoidal yapısı, yoğun kanlanması ve endotel döşemesindeki boşluklardır. Bütün bunlar, omur cismi tümör hücrelerinin implantasyonu ve proliferasyonu için biyokimyasal ve hemodinamik açıdan çok uygun bir ortam teşkil eder. ${ }^{[5]}$

\section{KLINIK}

Omurga metastazlarında en önde gelen semptom ağrıdır. Ağrı, hastalar tarafından çok iyi lokalize edilemeyebilir ve bu ağrının herhangi bir bel-sırt ağrısından ayırt edilmesi güç olabilir. Ancak, ağrının istirahatte de sürüyor olması, özellikle geceleri şiddetlenmesi, ilerleyici ve mekanik olmayan özellik taşımasının yanı sıra, ağrı kesicilere yanıtsız olması, ağrının malign bir kökeni olduğunu düşündürür. ${ }^{[3]}$ Erken dönemde aksiyel özellikte olan ağrının karakterine, hastalık ilerledikçe radiküler semptomlar da eklenebilir. Bir kanser hastasında açıklanamayan ve ilerleyici sırt-bel ağrısı durumunda, akla ilk olarak omurga metastazı gelmelidir.

B semptomları olarak adlandırılan, nedeni bilinmeksizin $38^{\circ} \mathrm{C}$ 'nin üzerine çıkan ateş, gece terlemesi, yorgunluk, genel halsizlik, isteksizlik ve nedeni bilinmeksizin altı ayda $10 \mathrm{~kg}$ ve üzeri kayıp olması gibi klinik tablolar da olası bir sistemik maligniteye işaret eder.

Omurga metastazı olan hastaların ilk olarak nörolojik bulgularla hekime başvurması daha nadir görülür. Aslında omurga metastazlı hastaların \%70'inde, hekime başvuru sırasında güçsüzlük bulunduğu, ancak hastayı hekime götüren nedenin, bu güçsüzlükten daha çok sürekli devam eden ağrı olduğu bildirilmiştir. [5] Nörolojik bulgular, genellikle yavaş başlar ve kendilerinden daha ön planda olan ağrı nedeniyle maskelenir. Hastalardaki ağrının ve nörolojik durumun nedeni, genellikle tümörün omurgada oluşturduğu destrüksiyon ve/veya bası iken, kimi zaman bu semptomların kaynağı patolojik kırıklar olmaktadır. Omurga metastazı bulunan bir hastada akut başlayan ağrı ya da var olan ağrıda ani bir artış akla patolojik kırığı getirmelidir. Özellikle ilerleyici nörolojik defisit durumunda acil cerrahi dekompresyon ihtiyacı doğabilir.

\section{RADYOLOJiK DEĞERLENDIRME}

Omurga metastazı bulunan olgularda tüm aksiyel iskelet öncelikle radyografik olarak değerlendirilmelidir. Omurga metastazlarının, \%15 oranında çoklu seviye hastalığı şeklinde olabileceği akıldan çıkarılmamalıdır. [3] Özellikle ön-arka grafide pedikül tutulumu nedeniyle pedikül gölgesinin silinmesi klasik bir bulgudur ve göz kırpan baykuş (winking owl) belirtisi olarak adlandırılır (Şekil 1). Omurgada destrüksiyona ait bulguların radyografik olarak saptanabilmesi için omur cisminin \%30-50'sinin yıkılması gereklidir. Ancak, metastaza bağı patolojik kompresyon kırıkları sıklıkla radyografik olarak görülebilir. Bilgisayarlı tomografi (BT) tetkiki her üç anatomik planı yüksek çözünürlükle değerlendirmede yardımcıdır ve omurga metastazını radyografiden altı ay önce saptayabilir. Oysa, özellikle mineralize dokuyu değerlendirmede çok üstün bir görüntüleme yöntemi olan BT ile belirgin destrüksiyon yaratmamış metastazların saptanması zordur. Manyetik rezonans (MR) görüntüleme omurga metastazlarını görüntülemede kullanılan en gelişmiş yöntemdir. MR, özellikle kemik iliği ile spinal kanal ve korda yönelik yüksek duyarlılık ve özgüllüğü sayesinde, intramedüller, ekstradural ve intradural metastazları göstermede, lezyonların oluşturduğu basıları saptamada çok yüksek performansa sahiptir. Omurga metastazlarını saptamada BT'nin tanısal duyarlılığı \%66,2 iken, MR kullanıldığında bu \%98,5'e çıkmaktadır. MR ile yapılan taramalarda metastatik lezyonlar T1 ağırlıklı sekanslarda hipointens, T2 ağırlıklı sekanslarda hiperintens görüntülenir. Omurga metastazı görüntülemesinde altın standart, kontrastlı tüm omurga MR incelemesidir (Şekil 2).

Omurga metastazlarının ayırıcı tanısında; osteoporoza bağlı patolojik kırıklar, primer tümörler ve omurgada destrüksiyon yaratan enfeksiyon hastalıkları yer alır. Osteoporotik patolojik kırıklar malign patolojik kırıklardan, BT'de yarık bulgusu (cleft sign) ve vakum fenomeninin varlığıyla; MR'de ise paravertebral yumuşak doku sinyalinin olmaması, omur cismi içinde yağ sinyalinin bulunması ve pedikül tutulumunun olmaması ile ayrılır. ${ }^{[5,6]}$ Primer omurga tümörleri metastazlardan, 


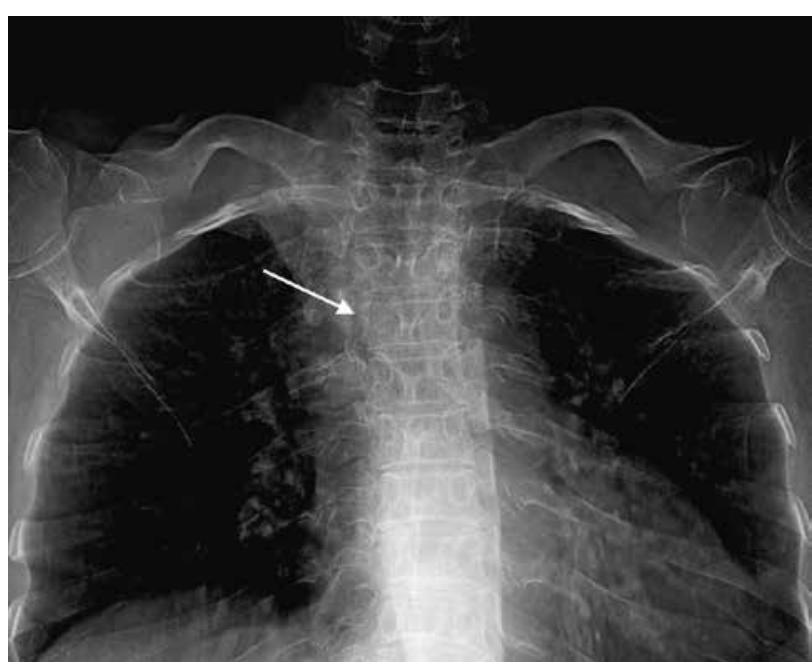

Şekil 1. Metastatik folliküler tiroid karsinomu olan 57 yaşında kadın hastada, T5 omurunun sağ pedikülünde, pedikül gölgesinin silindiğini gösteren, göz kırpan baykuş (winking owl) görünümü.

anatomik, radyolojik ve klinik özellikleri açısından farklılık gösterir. Primer omurga tümörlerinin büyük çoğunluğu benign karakterde olup, omurganın posterior elemanlarından kaynaklanır ve daha genç yaş grubunda daha sık görülür. Ancak, omurga metastazlarının \%5'inin posterior elemanlarda görüldüğünü de akıldan çıkarmamak gerekir. Enfeksiyonu ayırt etmenin en kolay yolu ise MR'de disk tutulumunun olup olmadığının ayrımının yapılmasıdır. Avasküler yapılar olan intervertebral diskler, teorik olarak metastazlara dirençli yapılardır. Omurgada disklerin intakt kaldığı destrüktif lezyonlar genellikle metastaz olarak değerlendirilir. Piyojenik spondilodiskit tanısında, elbette laboratuvarın da önemi büyüktür. Son dönemde metastaz ve enfeksiyonun ayrımında PET-BT'nin (pozitron emisyon tomografisi - bilgisayarlı tomografi) etkinliği üzerine birçok çalışma yapılmıştır. ${ }^{[7,8]}$

\section{TANI}

Omurga metastazı olan hastaların bir kısmı bilinen metastatik kanser hastası iken, bir kısmı bilinen herhangi bir metastazı bulunmayan kanser hastası, diğer bir kısmı da bilinen hiçbir kanser öyküsü olmayan hastalardır. Metastatik hastalığı olan hastalarda, genellikle, tipik görüntüleme bulguları nedeniyle tanı daha kolaydır ve sıklıkla lezyondan biyopsi yapılmasına ihtiyaç duyulmadan doğrudan tedaviye geçilir. Metastazı bulunmayan kanser tanılı hastalarda ise tedaviden önce bir tanı konması şarttır. Bu nedenle, hasta

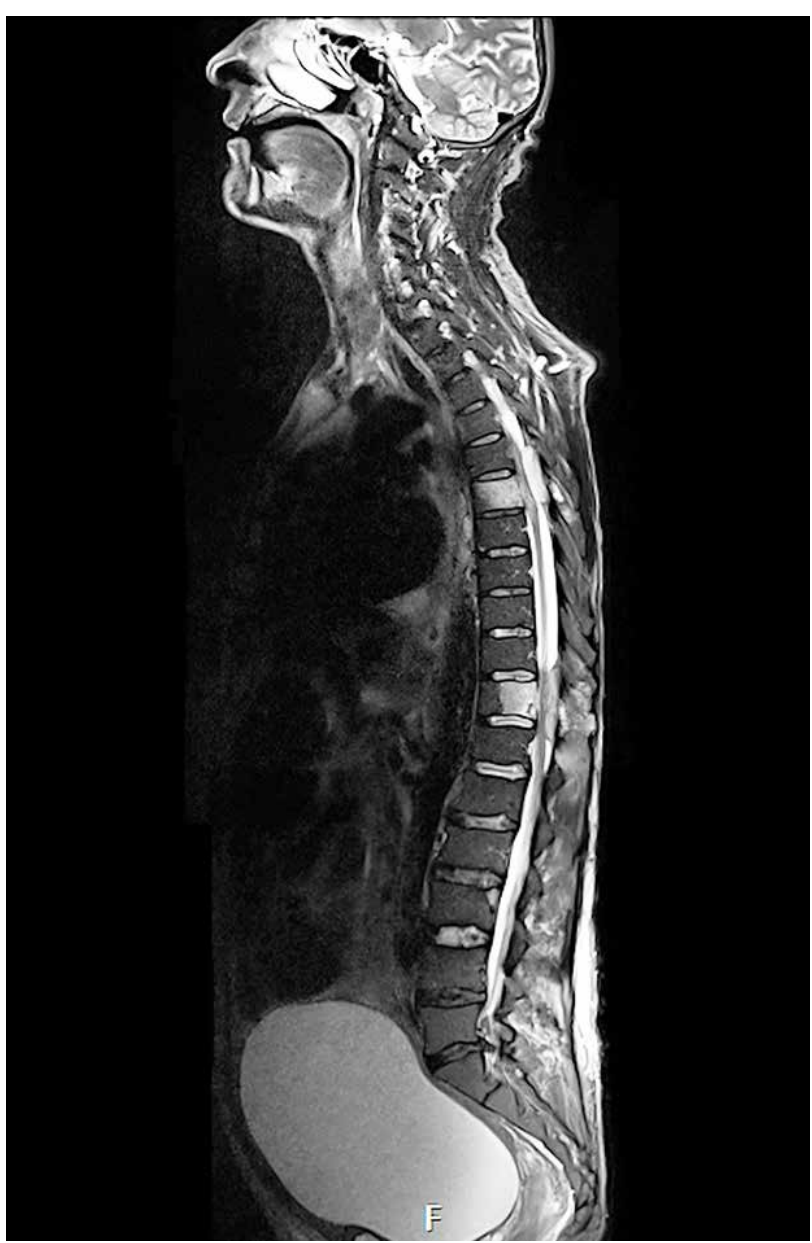

Şekil 2. Metastatik renal hücreli karsinomu olan 32 yaşında erkek hastanın tüm omurga kontrastlı MR görüntülerinde T6, T11 ve L3 omurlarında metastatik lezyonlar ve çoklu epidural kord basısı.

ayrıntılı bir tarama işleminden geçirilmeli, toraks ve batına yönelik BT tetkikleri yapılmalı, iskelet sistemi sintigrafik yöntemlerle taranmalı ve lezyonun bir metastaz olduğu biyopsi ile doğrulanmalıdır. Omurga metastazı olgularının yaklaşı \%20'si, bir primer kanser tanısı olmadan direkt omurga metastazı ile hekime başvurur. Bu tip olgularda tanı için daha önceden tanımlanmış bir strateji mevcuttur. Rougraff ve ark.; hastanın öyküsü, fizik muayene bulguları, rutin laboratuvar testleri, Teknesyum-99 fosfonat ile yapılan tüm vücut kemik sintigrafisi, radyografiler, toraks ve batına yönelik BT tetkiklerinden oluşan bu protokolü kullanarak, primeri bilinmeyen omurga metastazı olgularının \%85'inde primer tümörü saptayabildiklerini bildirmişlerdir. ${ }^{[9]}$ Yazarlar, bu olgulara biyopsi yapıldığında ise primer tümörü saptayabilme oranının 
\%93'e çıktığını ifade etmektedirler. Ayrıca, yazarlar bu protokol sayesinde hastalarda, omurga dışında, daha kolay biyopsi yapılabilecek lezyonların da saptanabildiğini belirtmektedirler. Primeri bilinmeyen olgularda ve omurga metastazlarını saptamada PET tek başına \%74 oranında doğru sonuç verirken, PET-BT ile bu oran \%98'e çıkmaktadır. ${ }^{[10]}$

Diğer tüm kemik ve yumuşak doku tümörlerinde olduğu gibi, omurga metastazlarında da biyopsinin hastayı tedavi edecek kişi tarafından yapılması bir kuraldır. Özellikle şüpheli omurga metastazı olgularında görüntüleme eşliğinde yapılan perkütan biyopsiler son yıllarda diğer yöntemlerin önüne geçmiştir. BT eşliğinde yapılan biyopsilerin, geneli itibarı ile \%89 oranında isabetli olduğu, bu oranın litik lezyonlarda \%93, sklerotik lezyonlarda ise $\% 76$ olduğu bildirilmiştir. ${ }^{[3]}$

\section{TEDAVIYE KARAR VERME}

Kanser hastalarında omurga metastazının varlığı, hastalığın sistemik bir hal aldığını gösteren bir durumdur. Bu nedenle, hastalar her yönden çok iyi değerlendirilmeli ve tedavinin şekline karar verirken multidisipliner anlayış içerisinde bulunulmalıdır. Sistemik hastalığı olan bir kanser hastasının yatağa bağlı kalması ömrünü ciddi derecede kısaltacaktır. Bu nedenle, kabaca söylemek gerekirse, omurga metastazı olan hastalarda cerrahi tedavi için üç aydan fazla sağkalım beklentisi, radyoterapi için ise bir aydan fazla sağkalım beklentisi yeterlidir.

Kanser hastalarında sağkalım beklentisinin değerlendirildiği birçok skorlama sistemi mevcuttur. Ancak, hastayı bütüncül olarak değerlendiren bu skorlama sistemleri, omurga metastazı olgularında kimi zaman tedaviyi şekillendirmede yetersiz kalır. Bu nedenle, ortopedik onkoloji pratiğinde omurga metastazları için üretilmiş skorlama sistemlerinin kullanılması daha büyük kolaylık sağlar. Bunlardan en bilineni Tomita ve ark. tarafindan geliştirilen skorlama sistemidir. ${ }^{[11]}$ Tomita skorlama sisteminde; hastadaki primer tümörün agresifliği, iç organ metastazları ve kemik metastazları değerlendirilerek bir karara varılır (Tablo 1). Yine Japonya kaynaklı bir diğer skorlama sistemi ise Tokuhashi ve ark. tarafından geliştirilendir. Bu sistemde ise, hastanın genel performansı, omurga ve omurga dışı kemik metastazları, iç organ metastazları, primer tümörün türü ve hastanın nörolojik durumu değerlendirilir. ${ }^{[12]}$ Gasbarrini ve ark.; hastanın opere edilebilirliği (ASA - American Society of Anesthesiologists skorlamasına göre), nörolojik durumu, primer tümörün onkolojik tedavilere olan yanıtı ve patolojik kırık varlığının değerlendirildiği skorlama sisteminin, hastalarda uzun dönem nörolojik fonksiyonlarında iyileşmeye yol açtığı ve daha uzun sağkalıma imkân oluşturduğunu ifade etmektedirler. ${ }^{[13]}$ Yine, uzun soluklu ve çok merkezli bir çalışma sonucu oluşturulan "spinal instabilite skoru" ise tümörün omurgadaki yerini, hastanın ağrı durumunu, metastazın radyografik tipini, omurganın dizilimini, patolojik kırıkları ve omurganın posterior elemanlarının etkilenme oranını değerlendiren, hastayı daha mekanik açıdan skorlayan bir sistemdir (Tablo 2). ${ }^{[14]}$

Skorlama sistemleri ile hastaya uygulanacak olan tedavi şekillendirilir. Cerrahi pencereden baktığımızda, omurga metastazı olgularına uygulanacak olan tedavileri; destekleyici (augmentative), dekompresif ve eksizyonel tedaviler olmak üzere üç ana başlık altında gruplandırabiliriz. Omurga metastazlı olgularda cerrahi endikasyonlar şu şekildedir:

- Radyoterapi, kemoterapi, hormonoterapi gibi cerrahi dışı yöntemlere yanıtsız ağrı

- Omurgada cerrahi dışı yöntemlerle ilerlemesi kontrol altına alınamayan destrüksiyon

- Olgunun radyoterapi için spinal kord tolerans sınırına ulaşmış olması

- Patolojik kırık, ilerleyici deformite ve nörolojik defisit ile karakterize instabilite

- Kemik, kemik debrisi ya da tümörden kaynaklanan ilerleyici nörolojik defisit ${ }^{[11]}$

Tedavi elbette hastaya göre düzenlenmelidir; ancak, kabaca bir tedavi algoritması oluşturmak gerekirse: ağrısı olan ancak instabilitesi ve nörolojik defisiti olmayan hastalara mümkün olduğunca cerrahi dışı (radyoterapi, hormonoterapi ve bisfosfonat tedavisi gibi seçeneklerle) yaklaşmak, eğer cerrahi yapılacaksa da perkütan vertebroplasti, kifoplasti ve radyoizotop tedavisi gibi seçenekleri tercih etmek akılcı olacaktır. ${ }^{[15]}$ İnstabilitesi olan olgularda eğer primer tümör radyosensitif ise intralezyonel eksizyon ve posterior enstrümantasyonun ardından radyoterapi kullanılmalıdır. Primer tümörün radyorezistan olduğu olgularda anterior-posterior dekompresyon ve enstrümantasyon ya da posterolateral dekompresyon ve posterior enstrümantasyon uygulanmalıdır. ${ }^{[1-3,5]}$

Eğer hasta soliter metastaz olarak bir omurga metastazına sahipse ve uzun dönem sağkalım beklentisi varsa, o zaman mevcut metastaz bir primer malign tümör gibi ele alınmalı ve hasta anterior korpektomi ya da en bloc spondilektomi ile tedavi edilmelidir. ${ }^{[11,16]}$

Omurga metastazı olgularında, ilerleyici nörolojik defisit acil tedavi endikasyonu doğurur. Böylesi bir durumda, ilk basamak tedavi yine radyoterapi olmalıdır. Ancak, nörolojik defisitin ilerleme hızı yüksekse veya primer tümör radyosensitif değilse spinal kordun ve/veya köklerin direkt dekompresyonu gündeme gelmelidir. ${ }^{[2,3,13]}$ 
Tablo 1. Omurga metastazları için Tomita skorlama sistemi ${ }^{[11]}$

\begin{tabular}{|c|c|c|c|c|c|c|}
\hline \multirow{3}{*}{ PUAN } & \multirow{2}{*}{\multicolumn{3}{|c|}{$\begin{array}{c}\text { EVRELEME } \\
\text { Prognostik faktörler }\end{array}$}} & \multirow{2}{*}{$\begin{array}{l}\text { Prognoza } \\
\text { yönelik } \\
\text { puan }\end{array}$} & \multirow{2}{*}{ Hedef } & \multirow{2}{*}{ Cerrahi strateji } \\
\hline & & & & & & \\
\hline & $\begin{array}{l}\text { Primer } \\
\text { tümör }\end{array}$ & $\begin{array}{l}\text { İç organ } \\
\text { metastazı* }\end{array}$ & $\begin{array}{l}\text { Kemik } \\
\text { metastazı }\end{array}$ & $\begin{array}{l}2 \\
3\end{array}$ & $\begin{array}{l}\text { Uzun dönem } \\
\text { bölgesel kontrol }\end{array}$ & $\begin{array}{c}\text { Geniş-marjinal } \\
\text { eksizyon }\end{array}$ \\
\hline 1 & $\begin{array}{c}\text { Yavaş } \\
\text { (meme, tiroid vb.) }\end{array}$ & & $\begin{array}{l}\text { Tek ya da } \\
\text { izole }\end{array}$ & $\begin{array}{c}4 \\
- \\
5\end{array}$ & $\begin{array}{l}\text { Orta dönem } \\
\text { bölgesel kontrol }\end{array}$ & $\begin{array}{c}\text { Marjinal-intralezyonel } \\
\text { eksizyon }\end{array}$ \\
\hline 2 & $\begin{array}{c}\text { Orta } \\
\text { (böbrek, uterus vb.) }\end{array}$ & $\begin{array}{l}\text { Tedavi } \\
\text { edilebilir }\end{array}$ & Çoklu & $\begin{array}{l}6 \\
7 \\
7\end{array}$ & $\begin{array}{l}\text { Kısa dönem } \\
\text { palyatif }\end{array}$ & Palyatif cerrahi \\
\hline 4 & $\begin{array}{c}\text { Hızlı } \\
\text { (akciğer, mide vb.) }\end{array}$ & $\begin{array}{l}\text { Tedavi } \\
\text { edilemez }\end{array}$ & & $\begin{array}{c}8 \\
-9 \\
-10\end{array}$ & $\begin{array}{c}\text { Terminal dönem/ } \\
\text { bakım }\end{array}$ & Destek tedavisi \\
\hline
\end{tabular}

* İç organ metastazı olmayan olgu=0 puan

** Omurga metastazları da dâhil kemik metastazları

Tablo 2. Spinal instabilite skoru*[14]

BíLEŞEN

SKOR

Tutulum

Bileşke (Oc-C2, C7-T2, T11-L1, L5-S1)

Hareketli omurga (C3-C6, L2-L4)

Yarı hareketli (T3-T10)

Hareketsiz (S2-S5)

İstirahat ve/veya yüklenme ile ağrı

Var

Aralıklı (mekanik olmayan)

Yok

Lezyonun radyografik özelliği

Litik

Mikst (litik/blastik)

Blastik

\section{Radyografik dizilim}

Subluksasyon/translasyon mevcut

De novo deformite (kifoz/skolyoz)

Normal dizilim

\section{Omur cisminde çökme}

Çökme >\%50

Çökme $<\% 50$

Tutulum >\%50 ancak çökme yok

Hiçbiri

Posterolateral yapılarda tutulum (faset, pedikül, kostovertebral bileşke vb.)

Bilateral

Unilateral

Hiçbiri

*Bu skora göre 0-6 puan stabilite, 7-12 puan potansiyel instabilite, 13 ve üzeri ise instabilite durumu olarak tanımlanmakta ve 7 puan üzerindeki olgularda omurga cerrahisi görüşü istenmesi gereği vurgulanmaktadır. 


\section{KAYNAKLAR}

1. Harel R, Angelov L. Spine metastases: current treatments and future directions. Eur J Cancer 2010;46(15):2696-707. Crossref

2. Quraishi NA, Gokaslan ZL, Boriani S. The surgical management of metastatic epidural compression of the spinal cord. J Bone Joint Surg Br 2010;92-B(8):1054-60. Crossref

3. Rose PS, Buchowski JM. Metastatic disease in the thoracic and lumbar spine: evaluation and management. J Am Acad Orthop Surg 2011;19(1):37-48. Crossref

4. Campanacci M. Metastatic bone disease. In: Campanacci M, editor. Bone and Soft Tissue Tumors. Padova: Piccin Nuova Libraria; 1999. pp.755-87.

5. Lewandrowski KU, Anderson ME, McLain RF. Tumors of the spine. In: Herkowitz HN, Garfin SR, Eismont FJ, Bell GR, Balderston RA, editors. Rothman-Simeone: The Spine, 6th ed. Philadelphia: Elsevier-Saunders; 2011. pp.1480-508.

6. Sarli M, Perez Manghi FC, Gallo R, Zanchetta JR. The vacuum cleft sign: an uncommon radiological sign. Osteoporos Int 2005;16(10):1210-4. Crossref

7. Kouijzer IJE, Scheper H, de Rooy JWJ, Bloem JL, Janssen MJR, vanden Hoven L, Hosman AJF, Visser LG, Oyen WJG, Bleeker-Rovers CP, de Geus-Oei LF. The diagnostic value of 18F-FDG-PET/CT and MRI in suspected vertebral osteomyelitis -a prospective study. Eur J Nucl Med Mol Imaging 2018;45(5):798-805. Crossref

8. Batouli A, Braun J, Singh K, Gholamrezanezhad A, Casagranda BU, Alavi A. Diagnosis of non-osseous spinal metastatic disease: the role of PET/CT and PET/MRI. J Neurooncol 2018;138(2):221-30. Crossref

9. Rougraff BT, Kneisl JS, Simon MA. Skeletal metastases of unknown origin. A prospective study of a diagnostic strategy. J Bone Joint Surg Am 1993;75(9):1276-81. Crossref
10. Dodwad SM, Savage J, Scharschmidt TJ, Patel A. Evaluation and treatment of spinal metastatic disease. In: Peabody TD, Attar S, editors. Orthopaedic Oncology. Chicago: Springer, Cham; 2014. pp.131-50. Crossref

11. Tomita K, Kawahara N, Kobayashi T, Yoshida A, Murakami $\mathrm{H}$, Akamaru T. Surgical strategy for spinal metastases. Spine (Phila Pa 1976) 2001;26(3):298-306. Crossref

12. Tokuhashi $\mathrm{Y}$, Matsuzaki H, Oda H, Oshima M, Ryu J. A revised scoring system for preoperative evaluation of metastatic spine tumor prognosis. Spine (Phila Pa 1976) 2005;30(19):218691. Crossref

13. Gasbarrini A, Cappucio M, Mirabile L, Bandiera S, Terzi S, Brabanti Brodano G, Boriani S. Spinal metastases: treatment evaluation algorithm. Eur Rev Med Pharmacol Sci 2004;8(6):265-74.

14. Fisher CG, DiPaola CP, Ryken TC, Bilsky MH, Shaffrey CJ, Berven SH, HArrop JS, Fehlings MG, Boriani S, Chou D, Schmidt MH, Polly DW, Biagini R, Burch S, Dekutoski MB, Ganju A, Gerszten PC, Gokaslan ZL, Groff MW, Liebsch NJ, MEndel E, Okuno SH, Patel S, Rhines DL, Rose PS, Sciubba DM, Sundaresan N, Tomita K, Vrga PP, Vialle LR, Vrionis FD, Yamada Y, Fourney DR. A novel classification system for spinal instability in neoplastic disease: an evidence-based approach and expert consensus from the Spine Oncology Study Group. Spine (Phila Pa 1976) 2010;35(22):E1221-9. Crossref

15. Anderson P. Samarium for osteoblastic bone metastases and osteosarcoma. Expert Opin Pharmacother 2006;7(11):147586. Crossref

16. Piccioli A, Maccauro G, Spinelli MS, Biagini R, Rossi B. Bone metastases of unknown origin: epidemiology and principles of management. J Orthop Traumatol 2015;16(2):81-6. Crossref 